\title{
COMPARISON CRITERIA FOR ICE ACCRETION ON AN AEROFOIL SURFACE
}

\author{
IFRAH MUSSA', QIAO WANG ${ }^{1}$, YUJING LIN¹ AND JIAN WANG ${ }^{1}$ \\ ${ }^{1}$ School of Engineering and the Environment \\ Kingston University, London, England, SW15 3DW, United Kingdom \\ E-mail: i.mussa@kingston.ac.uk, k1732218@kingston.ac.uk, y.lin@kingston.ac.uk, \\ j.wang@kingston.ac.uk
}

Key words: Ice Accretion, Rime Ice, Repeatability, Comparison Criteria.

\begin{abstract}
Ice accretion on aerofoils has been researched for many years for aircraft, rotorcraft and wind turbine blades using experimental and numerical techniques. While each method has some distinct advantages, it is the combination of the two strategies that is suggested to be the best way to understand and combat the icing challenge. However, both experimental and numerical techniques have certain limitations which can affect the droplet behavior and the resulting ice profiles. Therefore, when comparing numerically predicted ice shape with experimental data for validation purposes, it is important to account for the limitations of both techniques and identify how the two profiles were compared and deemed acceptable even when the two ice shapes appear to have geometrical discrepancies. Although most of the studies highlight the sources of error in their data, almost none of them explain the strategy employed to validate and verify their results. Furthermore, while the anti/de-icing is involved, energy consumption will be one key factor to consider. There should be a criteria to compare ice shapes from the same icing wind tunnel or results from different test facilities which can further help with comparison of numerical and experimental ice shapes. It would aid to set a standard to improve the quality of our research and make progress in the industry.
\end{abstract}

The aim of the present study is to propose criteria that could be used to compare experimental and numerical ice profiles on an aerofoil surface. Therefore, thorough, and meaningful discussion will be conducted in academic world and relevant industries.

The main features of the article are outlined as follows. A brief review on some of the experimental and numerical studies on ice accretion have been presented to discuss the methods used, highlight the technological advancements, and discuss key results and sources of error. Research shows that, in addition to the geometrical comparison, the performance of iced aerofoil must also be considered as a comparison strategy. Based on this analysis, the aim of comparing the ice shapes will be discussed. Following this, numerical results from current study are compared with experimental results to illustrate the necessity and importance of having the criteria. Next section will be devoted to proposing the preliminary criteria. Finally, the conclusion will be provided. 


\section{INTRODUCTION}

Icing is a major cause of concern for the aviation and wind energy industry due to performance and safety reasons [1-3]. Ice forms when small pieces of ice or supercooled water droplets collide with a cold structure. Since these droplets are in liquid form below zero degrees, they either freeze on impacting the surface or remain in their liquid form and freeze with a short delay [4]. The shape and type of ice formed depends on the atmospheric icing conditions where parameters such as; temperature, velocity, liquid water content (LWC) and median volumetric diameter (MVD) of the droplet play a significant role [5-7]. Depending on the atmospheric icing conditions, the ice formed could be rime ice or glaze ice. Technical reports from icing focused research groups suggest that rime ice forms at temperatures between $0{ }^{\circ} \mathrm{C}$ to $-20^{\circ} \mathrm{C}[8,9]$; while some researchers have reported it to form at temperatures as low as $-40{ }^{\circ} \mathrm{C}$ [10]. The possibility of rime ice to accrete at such low temperatures is due to its 'dry growth' process. As explained by [11], rime ice grows under dry conditions where water droplets freeze on contacting the surface which leads to air particles being trapped in the ice with no traces of liquid. This can happen at any temperature below $0{ }^{\circ} \mathrm{C}$ in the presence of fog or when the location of interest is at a higher altitude than the cloud base. Smaller water droplets create soft rime ice which has a density of 200 to $600 \mathrm{~kg} / \mathrm{m}^{3}$. It is white in appearance and has low to medium adhesion and cohesion to the substrate. However, large water droplets create hard rime ice with a density of 600 to $900 \mathrm{~kg} / \mathrm{m}^{3}$ hence it adheres strongly to the structure, but it is opaque in appearance. The shape of both soft and hard rime ice is said to be eccentric and pointing windward. Glaze ice

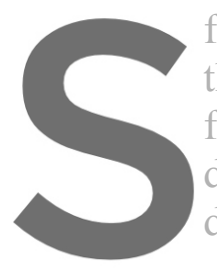
forms between $0^{\circ} \mathrm{C}$ to $-6{ }^{\circ} \mathrm{C}$. It is known to have "wet-growth because-unlike rime ice, not all
the water droplets freeze on impact and they remain in liquid form either trapped inside the
frozen ice or on the surface to freeze after a short delay. It appears to be transparent and has a
density of $900 \mathrm{~kg} / \mathrm{m}^{3}$ with strong adhesion forces. Glaze ice shape is said to have even
distribution and icicles $[8,9,11]$.
Researchers have conducted field studies, carried out experiments in icing wind tunnels and generated mathematical models to study ice accretion. While field studies could offer benefits

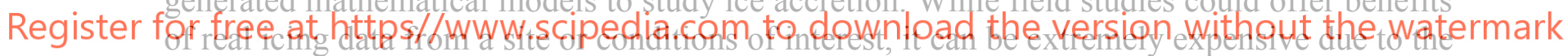

resources required and are sensitive due to the health and safety risks of the people involved.

Experiments on the contrary, despite being expensive and time consuming, offer a more controlled environment where a range of icing conditions can be tested, and the behaviour of water droplets can be observed more closely to record the ice formation process on a surface. However, depending on the case, experiments can be complicated and require some scaling laws to ensure the icing conditions in the wind tunnel are representative of the real conditions for a geometrically similar model. Due to the complexity of icing, the scaling laws also have limitations where parameters such as velocity and pressure could affect the resultant ice shape [12-14]. Experiments also require tests to be repeated a few times before the best results are selected. A study conducted by Shin and Bond [15] shows that repeatability of icing conditions does not affect the resulted ice shape for rime ice, but it does for glaze ice conditions. They further recorded drag value for each ice shape to compare performance which showed small difference in the drag data. Hence based on the performance, the repeatability was said to have provided good results. However, comparing the ice shapes obtained from different test facilities for the same model under the given icing conditions were reported to show bigger differences [16]. This highlights the complexity of icing experiments and the need for a criteria to compare 
experimental results from different test facilities. Another major concern for the experiments is recording the ice shapes which was originally done by tracing with pencils and using hot plate $[15,16]$ but advanced techniques have allowed the use of laser scanning [17] or digital image projection based scanning [18].

Ice accretion can also be predicted numerically which reduces the time and expensive testing cost in conducting icing wind tunnel experiments or field studies. The computational techniques are especially more cost effective as they reduce the time it takes to test a wide range of icing scenarios and operational conditions, and develop and estimate the efficiency of ice prevention system. Although numerical methods propose a spectrum of benefits, they still require experimental data for validation purposes $[9,19]$.

Mathematical models analyse the fluid-structure interaction of an object exposed to icing climate. The first step in predicting ice shapes using a software is to capture the flow field around the object. The aerodynamic data assists to identify the trajectories of water droplets which helps compute the rate of impingement of these droplets on the object. Ice shape is then predicted by coupling the droplet collection efficiency data with the thermodynamic model. The predicted ice shape can then be used to study the aerodynamic penalties of iced object and assess heating requirement by either a de-icing system to remove this ice or an anti-icing system to prevent this ice from accreting on the object [9, 19-22].

Numerical techniques also come with a set of limitations. Firstly, since nearly all the ice prediction tools are developed using slightly different physical models, the user must be aware of the limitations of the codes prior to using any of them for their specific simulation
requirements [9]. Furthermore, the size of the computational domain, grid type and grid
generation techniques, and boundary conditions applied for simulations nust be dond
meticulously. Grid generation for iced aerofoil is much more challenging where research/into
different topologies such as [23-25] provides a good guidance.
Due to these different experimental and computational ice prediction techniques and the limitations associated with them leads to differences in the results under any given icing

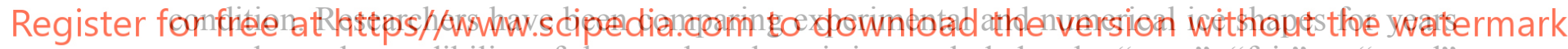
to evaluate the credibility of the results where it is concluded to be "poor", "fair" or "good" [26]. Several studies have therefore been conducted to highlight the importance to quantify the results and proposed different ways to compare them [15, 16, 26-29]. However, most of the studies either suggest a quantitative analysis of the two ice shapes or comparing aerodynamic performance particularly drag coefficient. Therefore the purpose of this paper is to build on existing knowledge and propose a comparison criteria for ice shapes formed on an aerfoil. For the purpose of this study, only rime ice comparison is proposed here.

\section{METHODOLOGY}

\subsection{Experimental data}

NACA0012 aerofoil was selected for the analysis. Since it is a widely tested aerofoil for a range of research purposes, it makes it easier to find experimental data for validation purposes of the current study. Two sets of icing experimental data were selected to compare with the numerical results. The icing wind tunnel tests were conducted under the same conditions in different test facilities. The test blade at both facilities had the same chord length of 36 inches and angle of attack of $3^{\circ}$, but the blade was setup differently in the test sections. The reason for 
selecting these experimental data were to investigate how different experimental techniques affect the resulting ice shape and how well they compare with the numerical results.

The two test facilities selected are Cox \& Co. and China Aerodynamic Research Development Centre (CARDC). The test conditions are based on the Aerospace Information Report (AIR) 5666 as highlighted in Table 1 [16]. The results from Cox were extracted from the AIR5666 report whereas the results from CARDC were obtained as part of collaboration on the current research.

Between the two test facilities, Cox installed the test blade horizontally where only one reading across the blade span was taken. However, CARDC installed the test blade vertically and took three readings along the blade height i.e., upper, middle and bottom section of the blade. Figure 1 shows the experimental ice shapes obtained from the two facilities. In terms of geometrical appearance, it is evident that the Cox ice profile matches well with the upper section of the CARDC test blade. Therefore, these profiles can be taken further for numerical validation. It is worth highlighting that the test model in the repeatability study [15] was also installed vertically in the test section and it was reported that the ice mass at the top of the test section was less than that of the mid or bottom section. This led them to suggest that the midsection would be the optimum location to record the ice shapes. The quantification study [18] on the contrary had the test model installed horizontally where variations in ice shapes were recorded along the span. The maximum combined outer boundary of the ice profiles at different cross-sections was taken as the final ice shape. This suggests the recording of data therefore can vary depending on the testing technique and facilit

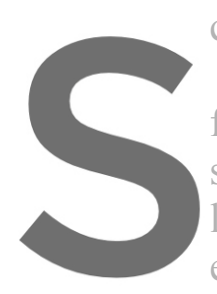
Prior to eliminating the other two profiles
further analysis, it is important to understand w
section of the CARDC ing blade are pot the
linked with the experimental technique and the experiments, the non-uniformity of the flow
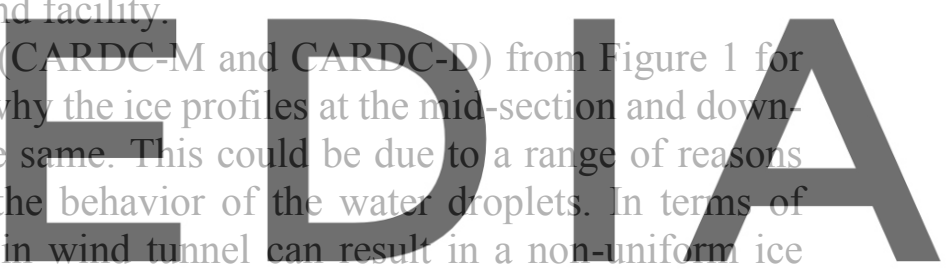

shape. Furthermore, if there is no wall treatment on the wall of the test section then the boundary

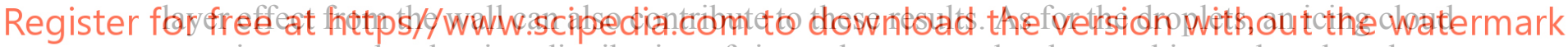
contains water droplets in a distribution of sizes where some droplets are bigger than the others. Droplets that are bigger than $50 \mu \mathrm{m}$ are known as supercooled large droplets (SLD). Smaller droplets have smaller mass and inertia which tends to follow the flow streamlines, however, SLD have higher mass and inertia which leads a fraction of them to follow the path line and collide with the surface. The gravitational forces on these droplets are relatively higher than the other droplets which influences their trajectories. Further to this, it is important to acknowledge that when the droplets are flowing at high speeds, they have the tendency to deform, merge or break before reaching the surface. Therefore, even if the droplet diameter is set to be constant in the icing wind tunnel, it can alter subject to the droplets behavior they may experience under different circumstances [30,31]. 
Table 1: Icing condition for rime ice

\begin{tabular}{lccccccc}
\hline $\begin{array}{l}\text { Icing } \\
\text { Type }\end{array}$ & $\begin{array}{c}\text { Static } \\
\text { Temperature } \\
{ }^{\circ} \mathrm{C}\end{array}$ & $\begin{array}{c}\text { LWC } \\
\mathrm{g} / \mathrm{m}^{3}\end{array}$ & $\begin{array}{c}\text { Droplet } \\
\text { Size } \\
\mu \mathrm{m}\end{array}$ & $\begin{array}{c}\text { Speed } \\
\mathrm{m} / \mathrm{s}\end{array}$ & $\begin{array}{c}\text { Icing } \\
\text { Duration } \\
\text { min }\end{array}$ & Re & $\begin{array}{c}\text { AIR Test } \\
\text { Condition }\end{array}$ \\
\hline Rime & -30 & 0.5 & 20 & 90 & 20 & $7 \times 10^{6}$ & 8 \\
\hline
\end{tabular}

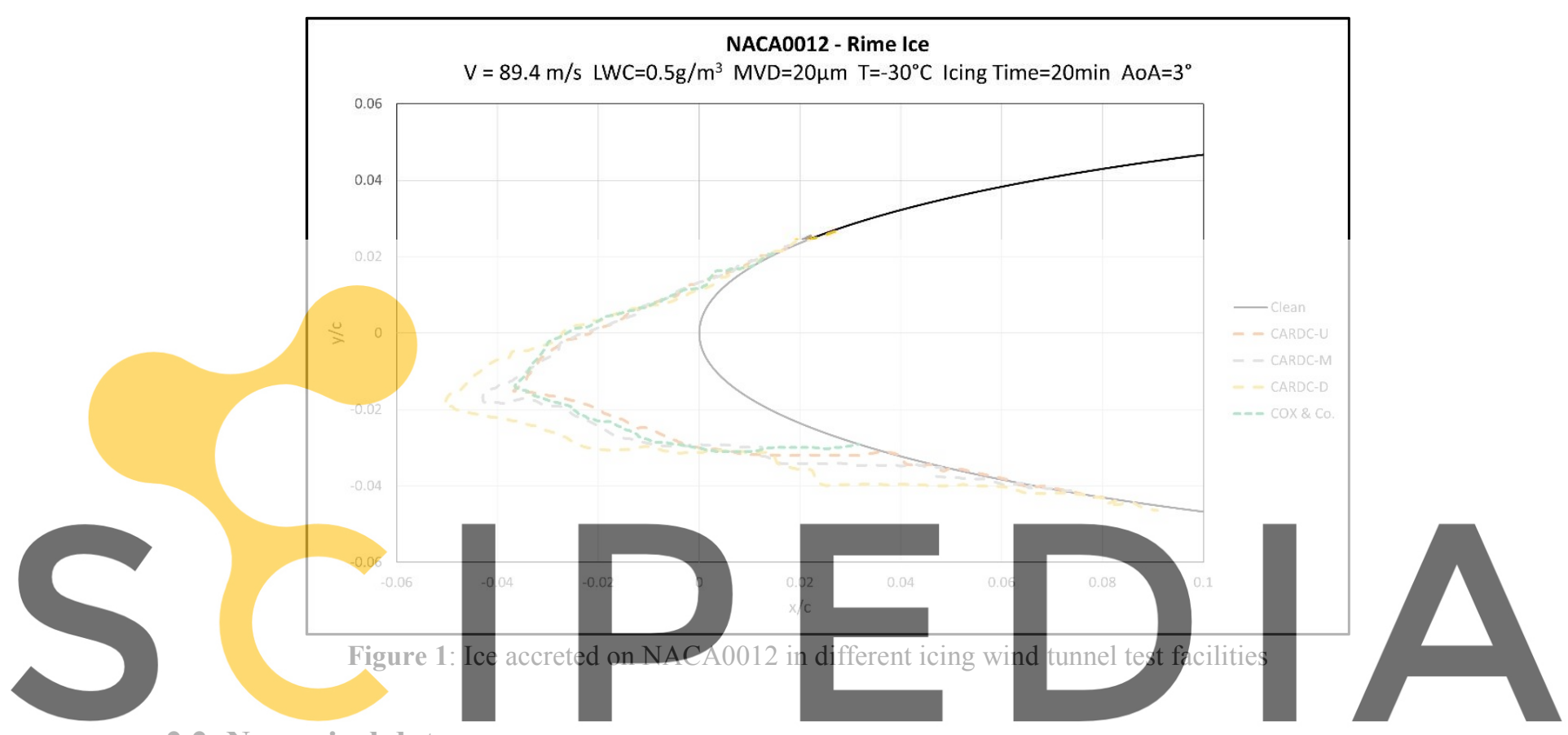

2.2 Numerical data

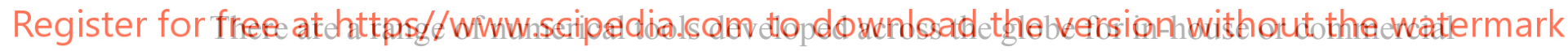

use to predict ice shapes. Some of these codes include LEWICE (USA), TRAJICE (UK), CANICE and FENSAP-ICE (Canada), CIRA and MULTICE (Italy) and ONERA (France) [9, 32]. Among these codes LEWICE and FENSAP-ICE are the most widely used commercially available software for ice accretion investigation [21, 33-42]. FENSAP-ICE is used to predict ice for this study as it is found to be better than LEWICE for rime ice cases [2], and is also found to be capable of producing reasonably good results for glaze ice [43].

FENSAP-ICE has a modular structure. First, the flow field is resolved using Navier-Stokes equations with FENSAP flow solver module. Second, the droplets collection efficiency is captured using the Eulerian method under DROP3D. Third, the ice accreted on the surface is predicted with the help of the shallow-water icing model under ICE3D. These three modules work separately but they have a complete interactive loop. This allows the users to conduct simulations in a single time interval (Single Shot), or in a time-iterative process (Multi Shot) where its powerful re-meshing engine adjusts the original mesh to the new iced profile $[2,21$, 43]. It also allows users to conduct flow analysis using Fluent or CFX [44]. Therefore, for the purpose of this study, Fluent is selected as the flow solver and FENSAP-ICE is used to conduct Multi Shot analysis. 
A C-grid structured mesh was generated using ANSYS ICEM. The inlet, outlet and farfield boundaries were set to 20 meters chord length away from the aerofoil. A mesh independent study was conducted to ensure an optimum mesh is selected for the study. Steady-state Fluent flow simulations were set up using pressure-based solver, K- $\omega$ SST turbulence model and Coupled scheme. Once the flow simulations converged, the DROP3D simulations were conducted using SLD by body forces to account for the splashing and break-up model along with the gravitational force on the droplets. A similar setup was then used for ICE3D simulations with the addition of beading model to allow the solver to predict sand-grain roughness height on the surface caused by moving and freezing beads [43]. To conduct a multi shot analysis, the icing time was divided into 12 shots as it was found to be the optimal set-up for this study.

\section{RESULTS AND DISCUSSION}

Figure 2 shows the numerical ice shape results using FENSAP-ICE compared with the experimental Cox and CARDC ice shapes. As expected, the numerical ice shape has some differences compared to experimental ice shapes from both test facilities. Despite these differences, it can be argued that given the limitations and techniques employed in both methods, the results are comparable as the numerical ice profile closely follows the contour of the other two ice shapes in certain areas. However, this explanation alone is not sufficient to deem these results acceptable. While there would always be limitations and various sources of

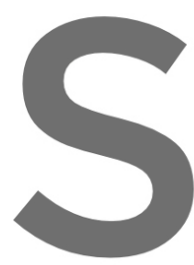
errors in each method, results. The two-criterio of the three ice shapes
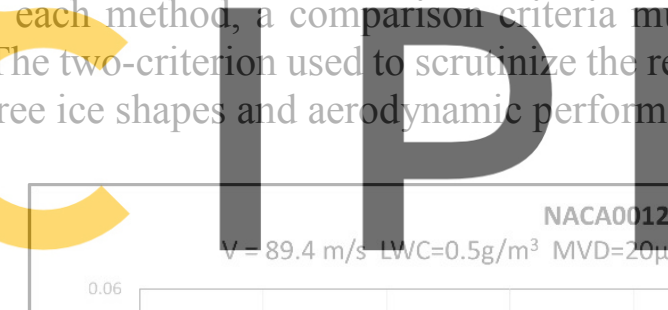

$9.4 \mathrm{~m} / \mathrm{s} L \mathrm{~W} C=0.5 \mathrm{~g} / \mathrm{m}^{3} \mathrm{MVD}=$
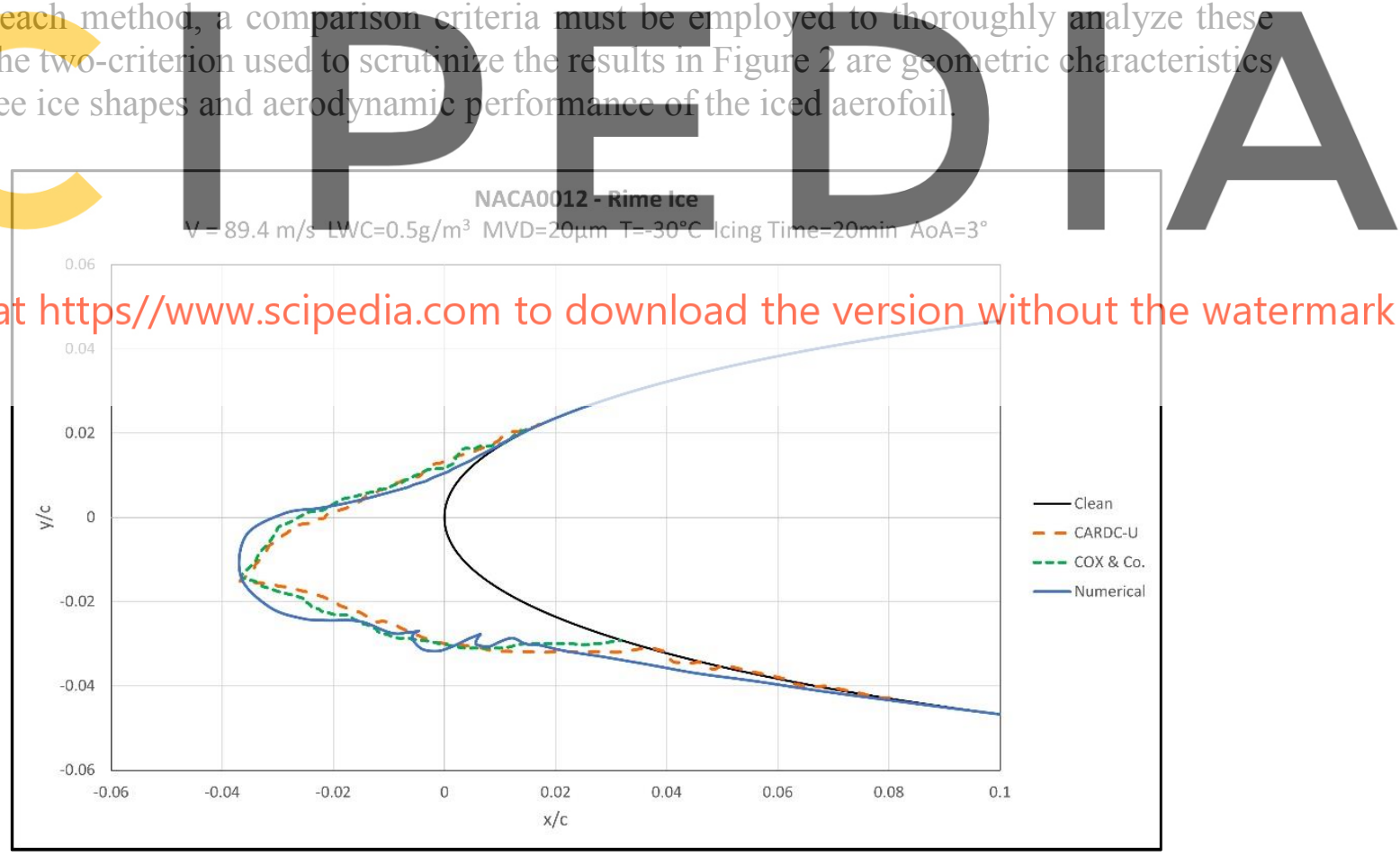

Figure 2: Numerical ice shape result against experimental ice shapes

\subsection{Geometric comparison}

To compare the geometric characteristics of the three rime ice shapes, an in-house code was 
used to quantify the results as it was originally suggested in AIR5666 report [16] for glaze ice profiles. For the rime ice profiles in this study, five key characteristics were examined. These characteristics were upper icing limit, lower icing limit, lower horn angle, lower horn peak thickness, and total ice area. Figure 3 illustrates reference points for the four former parameters. Quantified results of the three ice shapes are highlighted in Table 2.

\subsubsection{Upper icing limit}

Upon investigation of the upper icing limit, it may seem from Figure 3 that CARDC's result is furthest away from the origin; however, it is Cox that is calculated to be the furthest of the three at $0.0299 \mathrm{~m}$. Compared to Cox, the value for numerical upper icing limit is hence $9 \%$ less making it closer to the origin. It should further be noted that both experimental ice shapes have roughness in the upper icing limit, however the numerical ice prediction is not capable of predicting this roughness. As a result, the experimental ice profile depicts an irregular ice profile in this region as opposed to the numerical ice contour which smoothly blends into the aerofoil profile.

\subsubsection{Lower icing limit}

The lower icing limit has bigger difference across all three profiles. Figure 3 depicts that the lower icing limit from Cox stops around $0.03 \mathrm{~m}$ however it then gradually blends into the aerofoil surface around $0.0421 \mathrm{~m}$ away from the origin. CARDC profile on the contrary

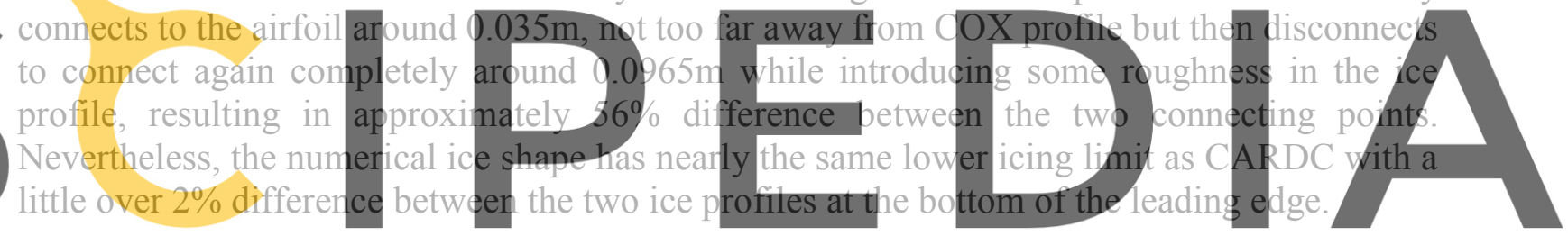

\subsubsection{Lower horm angle}

Register for free at https//WWW.scipedia.com to download the version without the watermark Since the horn formed in this rime ice profile is below $Y=0$ point from the origin, it is referred to as the lower horn angle. Among all the five characteristics studied for this case, lower horn angle has the least amount of difference. The results from Cox and the numerically predicted ice shape gives an angle of $201^{\circ}$ while CARDC gave $0.5 \%$ higher with $202^{\circ}$.

\subsubsection{Lower horn peak thickness}

The thickness of the lower horn for all three ice profiles is in fair agreement with each other. The maximum horn thickness is $0.0389 \mathrm{~m}$ which is obtained from CARDC whereas the lowest horn thickness is $0.0380 \mathrm{~m}$ obtained from Cox. The difference between these two values is approximately $2 \%$. The lower horn thickness for numerical ice is recorded to be in between Cox and CARDC which provides an approximate difference of $1 \%$.

\subsubsection{Total ice area}

Although the ice profile recorded from CARDC adheres closer to the origin at the top of the leading edge and narrows as it protrudes to form the lower ice horn; its total ice area is $10 \%$ higher than Cox. This is primarily because Cox's lower icing limit is closest to the origin while 
CARDC's ice profile has additional roughness from separation and reattachment of ice at the bottom of the leading edge. It is evident from Figure 3 that numerical ice captures the maximum ice area which compared to CARDC is found to be $40 \%$ higher.

Upon investigation of the numerical results with both the experimental results from Cox and CARDC in Table 2, it can be established that the results from the numerical ice prediction share less differences with the results from CARDC than Cox. CARDC's results compared to the numerical data have a minimum difference of $0.5 \%$ for lower horn angle and the highest difference of $40 \%$ for total ice area across all five ice characteristics. Whereas Cox's results compared to the numerical results show a minimum difference of $1 \%$ for lower horn peak thickness and a maximum difference of $135 \%$ for lower icing limit across four ice characteristics. The only similarities between the results for the numerical data and the data from Cox is the lower horn angle.

Following all numerical ice prediction simulations conducted for this case, it is crucial to highlight that the numerical results failed to capture the pointed profile of the lower horn that has been achieved from both experiments. Furthermore, unlike experimental measurements, numerical analysis failed to capture ice surface roughness for this rime ice case. The numerical ice profiles provided a simple rounded leading-edge profile with slight irregularities at the bottom to depict roughness. One of the major reasons for the geometric difference between the experimental and numerical profiles could be due to the simplifications introduced in the

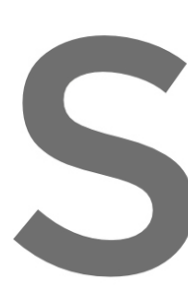
software codes to offer

\section{real behavior of the diroplets.}

Register for free at https//www.scipedia.com to download the version without the watermark

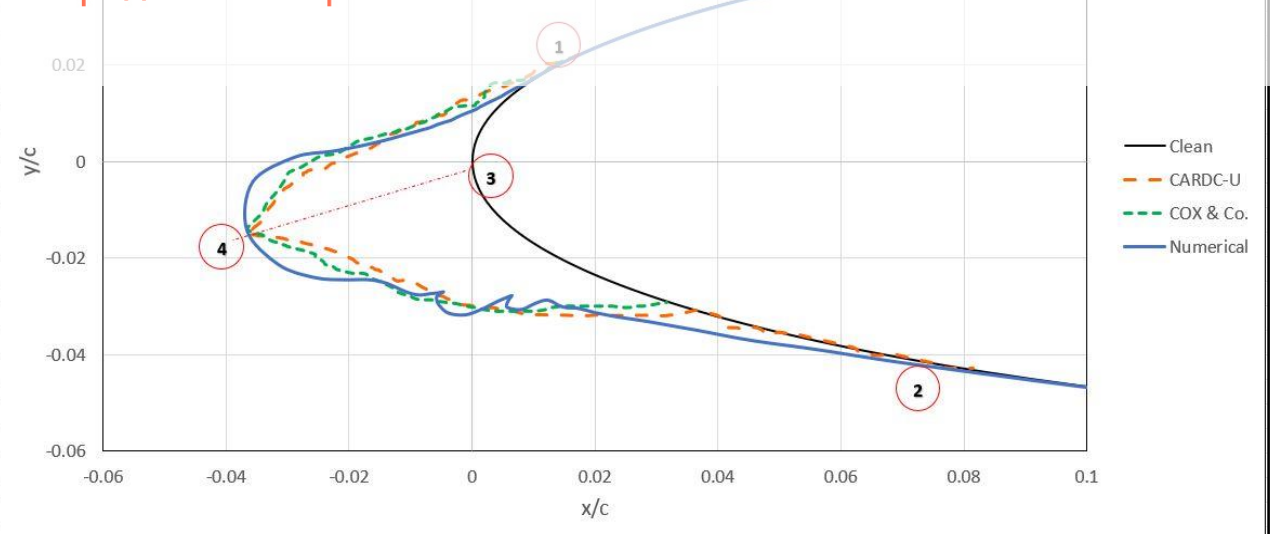

Figure 3: Geometric characteristics for rime ice profile showing 1. Upper icing limit 2. Lower icing limit 3. Lower horn angle 4. Lower horn peak thickness 
Table 2: Quantified results of ice shapes

\begin{tabular}{llccc}
\hline & & CARDC & Cox & Numerical \\
\hline 1 & Upper Icing Limit $(\mathrm{m})$ & 0.0290 & 0.0299 & 0.0272 \\
\hline 2 & Lower Icing Limit $(\mathrm{m})$ & 0.0965 & 0.0421 & 0.0988 \\
\hline 3 & Lower Horn Angle $\left({ }^{\circ}\right)$ & 202 & 201 & 201 \\
\hline 4 & Lower Horn Peak Thickness $(\mathrm{m})$ & 0.0389 & 0.0380 & 0.0385 \\
\hline 5 & Total Ice Area $\left(\mathrm{m}^{2}\right)$ & 0.0010 & 0.0009 & 0.0014 \\
\hline
\end{tabular}

\subsection{Performance Comparison}

For the purpose of this study, computational analysis of the aerodynamic performance is compared only for the clean and numerically predicted ice result. Figure 4 illustrates the velocity, pressure and turbulent kinetic energy contour plots for both clean and numerical ice aerofoil.

Interestingly, the clean aerofoil produced a lift coefficient of 0.3103 and the iced aerofoil experienced an increase in lift coefficient by $0.4 \%$ with a value of 0.3115 . The drag coefficient on clean aerofoil was recorded to be 0.0075 , and 0.0084 for the iced aerofoil, giving an increase of $12.2 \%$.

The increase in lift for iced aerofoil can be explained by the smooth curvature of ice shape at the leading edge where the leading-edge radius is reduced compared to the original aerofoil. This curved lower horn increased shear forces on at the front edge of the flow mixes with the onin the dimple and increased turbulent kinetic energy due to the recirculation zone can be seen Register forfficeee att (t).ttps//www.scipedia.com to download the version without the watermark

Rough ice features at the bottom surface of the leading edge also indicate separation. However, the flow is not reattached causing the separation location at the bottom surface to shift forward compared to the clean aerofoil which explains the increase in drag. These small rough surfaces sometimes act as horns resulting in multiple stagnation points which degrades the aerodynamic performance.

Comparing the clean and iced aerofoil aerodynamic performance highlights the importance of capturing the ice shapes accurately as the iced aerofoil performance analysis could sometimes lead to unexpected results. Since the numerical ice shape is relatively smoother, the increase in lift is justified. However, results from experiments exhibit pointed horn with more roughness. Therefore, additional simulations were conducted to analyse flow around the two experimental ice shapes in Figure 2 and 3 from Cox and CARDC. Compared to the clean aerofoil, Cox ice shape showed a decrease in lift by $1.1 \%$ while CARDC showed a decrease by $1.4 \%$. Examining the drag coefficient value, Cox showed an increase in drag by $13 \%$ compared to the clean aerofoil whereas CARDC showed a $20.4 \%$ increase. Surprisingly, despite the fact that Cox ice shape had the least amount of geometric similarities with the numerically predicted ice shape, they both produced almost the same amount of drag. This suggests that rime ice can be predicted numerically to emulate the experimental ice results. Comparing ice shapes from 
the two test facilities, it can further be deduced that CARDC's ice shape from the upper section of the test blade, where the least amount of ice was formed, produced 7\% more drag than Cox's ice shape. A more detailed aerodynamic analysis of the three ice shapes will be captured in future publication.

\section{CONCLUSIONS}

Ice prediction techniques play a crucial role in ice formation. Different experimental and numerical techniques can produce ice shapes that may appear to be following a similar trend but there would still be some discrepancies in the geometric characteristics of the ice shapes. The purpose of this study was to compare experimental rime ice results recorded in two different test facilities, Cox and CARDC, under similar icing conditions but different installation methods of the icing blade in the test section. Cox installed the test blade horizontally while CARDC installed the test blade vertically. The ice shapes from these experiments were then compared with the numerical ice shapes predicted using FENSAP-ICE.

Following an in-depth analysis, this study proposes to scrutinize the geometric characteristics of the rime ice shapes highlighting five main areas; the upper icing limit, lower icing limit, lower horn angle, lower horn peak thickness, and total ice area. Furthermore, the aerodynamic performance must also be investigated to observe how ice shapes perform in comparison to each other despite the differences in their profile.

Quantification of ice shapes revealed that the experimental and numerical ice shapes formed

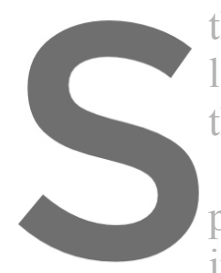

the same lower horn an

lower icing limit where

than the numerical ice

Aerodynamic analys

prediction resulted in the

increased by $12 \%$. The increase in drag was caus
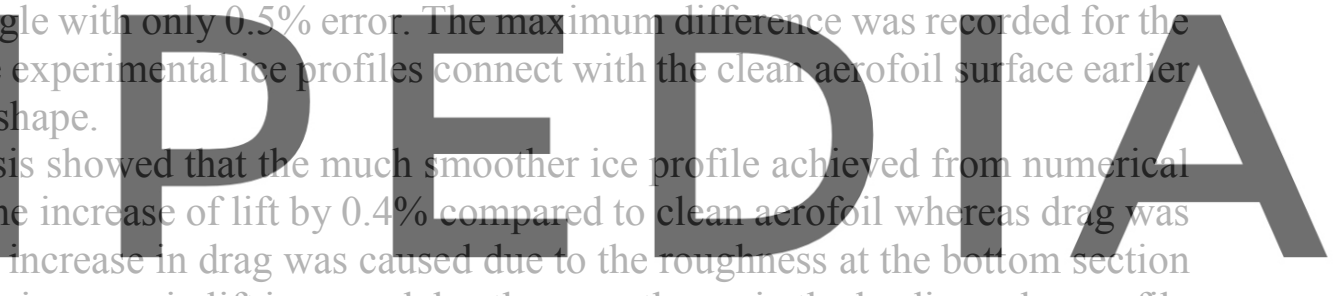

of the leading edge. The increase in lift is caused due the smoothness in the leading-edge profile

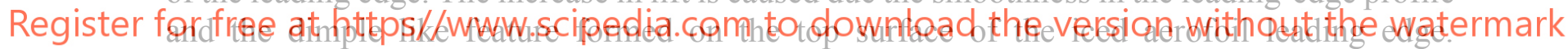

Subsequent research involves an in-depth aerodynamic analysis of clean and iced aerofoil profilies.

It is evident that a comparison criteria is needed to validate ice shapes. This would help improve experimental techniques and develop additional advanced numerical models to replicate the behavior of water droplets. Hence, this will improve the accuracy of both experimental and numerical ice prediction and thus offer sustainable solutions. 


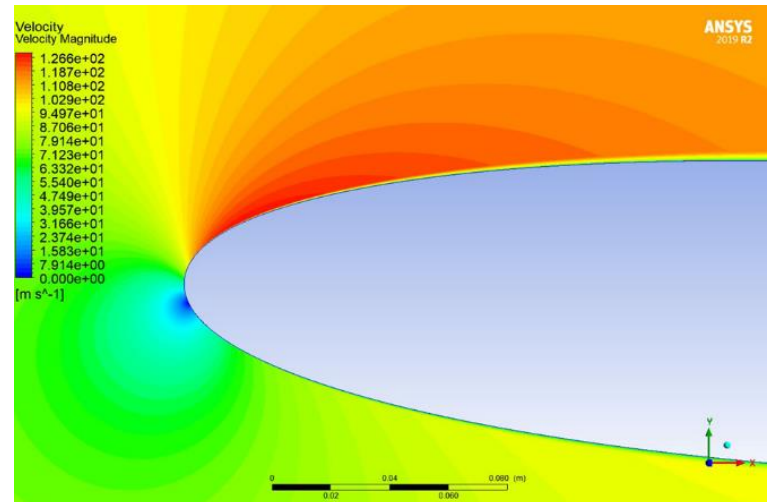

a. Velocity contour for clean aerofoil

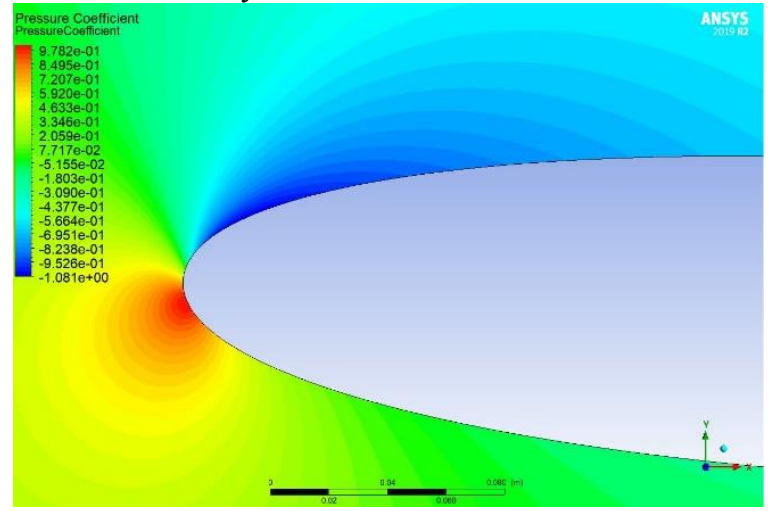

c. Pressure contour for clean aerofoil

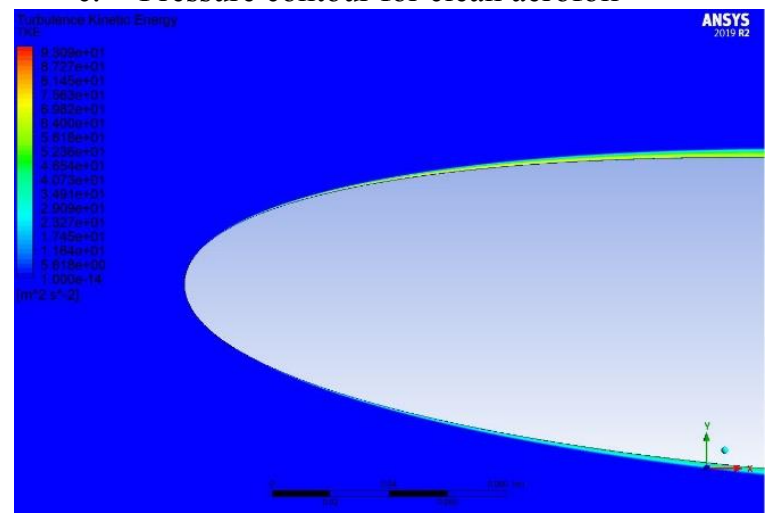

e. Turbulent kinetic energy for clean aerofoil

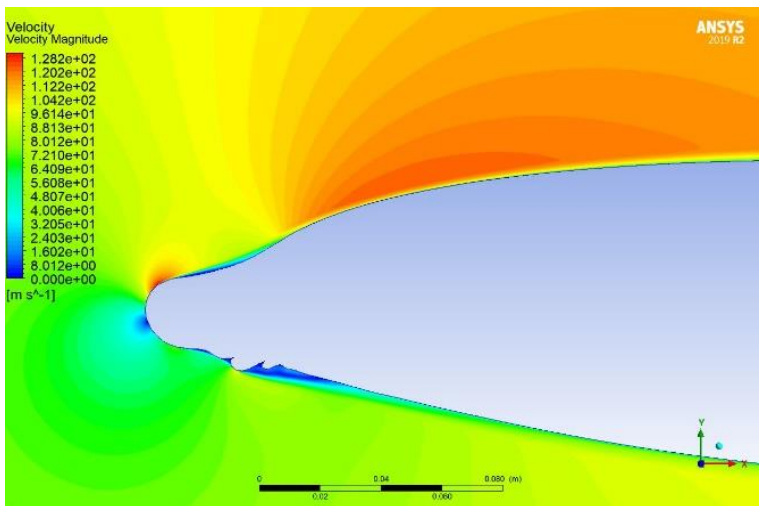

b. Velocity contour for numerical iced aerofoil

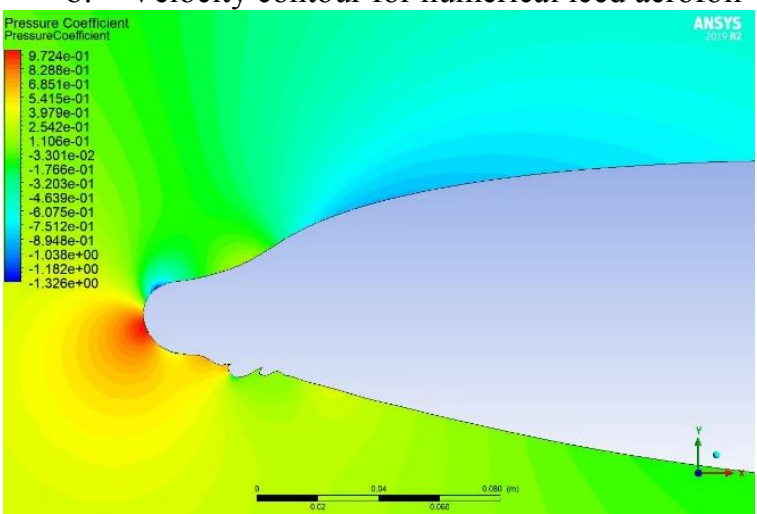

d. Pressure contour for numerical iced aerofoil

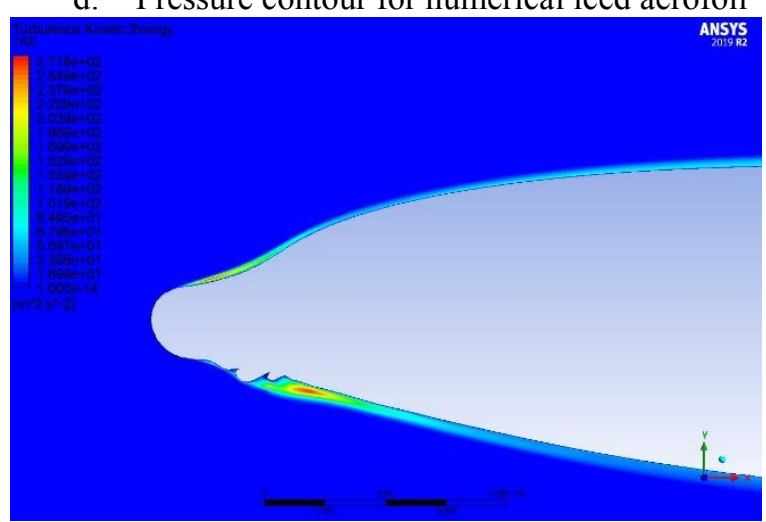

f. Turbulent kinetic energy for numerical iced aerofoil

Figure 4: Aerodynamic analysis of clean and numerical ice shape 


\section{REFERENCES}

[1] G. E. C. Fujiwara and M. B. Bragg, "3D Computational Icing Method for Aircraft Conceptual Design," in 9th AIAA Atmospheric and Space Environments Conference, Denver, Colorado, 2017.

[2] R. Hann, "UAV Icing: Comparison of LEWICE and FENSAP-ICE for Ice Accretion and Performance Degradation," in 2018 Atmospheric and Space Environments Conference, Atlanta, Georgia, 2018.

[3] S. Barber, Y. Wang, N. Chokani and R. S. Abhari, "The Effect of Ice Shapes on Wind Turbine Performance," in 13th International Workshop on Atmospheric Icing of Structures (IWAIS XIII) 2009, Andermatt, Switzerland, 2009.

[4] S. G. Pouryoussefi, M. Mirzaei, M.-M. Nazemi, M. Fouladi and A. Doostmahmoudi, "Experimental Study of Ice Accretion Effects on Aerodynamic Performance of an NACA 23012 airfoil," Chinese Journal of Aeronautics, vol. 29, no. 3, pp. 585-595, 2016.

[5] D. R. Miller, M. G. Potapczuk and T. J. Langhals, "Preliminary Investigation of Ice Shape Sensitivity to Parameter Variations," in 43rd AIAA Aerospace Sciences Meeting and Exhibit, Reno, Nevada, 2005.

[6] D. R. Miller, M. G. Potapczuk and T. J. Langhals, "Additional Investigations of Ice Shape Sensitivity to Parameter Variations," in 44th AIAA Aerospace Sciences Meeting and Exhibit, Reno, Nevada, 2006.

[7] J. G. Pallarol, B. Sunden and Z. Wu, "On Ice Accretion for Wind Turbines and Influence of Some Parameters," in Aerodynamics of Wind Turbines, UK, WIT Press, 2015, pp. 129160.

[8] S. Fikke, G. Ronsten, A. Heimo, S. Kunz, M. Ostrozlik, P. -E. Persson, J. Sabata, B. Wareing, B. Wichura, J. Chumm, T. Laakso, K. Santi and L. Makkonen, "COST 727: Atmospheric Icing on Structures Measurements and Data Collection on Icing: State of the Art," MeteoSwiss, Switzerland, 2006.

[9] IEA Wind Task 19, "Available Technologies for Wind Energy in Cold Climates - report - 2nd Edition," IEA Wind, 2018.

[10] O. Yirtici, I. H. Tuncer and S. Ozgen, "Ice Accretion Prediction on Wind Turbines and Consequent Power Losses," in Journal of Physics: Conference Series, 2016.

[11] L. Makkonen, "Models for the Growth of Rime, Glaze, Icicles and Wet Snow on structures," Phil. Trans. R. Soc. A., vol. 358, p. 2913-2939, 2000.

[12] G. A. Ruff, "Analysis and Verification of the Icing Scaling Equations," Arnold Engineering Development Centre, Tennessee, 1986.

[13] D. N. Anderson, "Manual of Scaling Methods," NASA Glenn Research Centre, Cleveland, 2004.

[14] X. Yi and G. L. Zhu, "Study on Icing Test Scaling Law," in Proceedings of the Fifth International Conference on Fluid Mechnaics, Shanghai, 2007.

[15] J. Shin and T. Bond, "Results of an Icing Test on a NACA 0012 Airfoil in the NASA Lewis Icing Research Tunnel," in 30th Aerospace Sciences Meeting \& Exhibit, Reno, Nevada, 1992. 
[16] AC-9C Aircraft Icing Technology Committee, "Icing Wind Tunnel Interfacility Comparison Tests," SAE International, 2012.

[17] Z. Long, G. Longde and Y. Jianjun, "Investigation of Ice Shape Measurement Technique Based on Laser Sheet and Machine Vision in Icing Wind Tunnel," in Fifth International Conference on Image and Graphics, Xi'an, Shanxi, 2009.

[18] L. Gao, R. Veerakumar, Y. Liu and H. Hu, "Quantification of the 3D Shapes of the Ice Structures Accreted on a Wind Turbine Airfoil Model," The Visualization Society of Japan, vol. 22, no. 4, p. 7, 2019.

[19] S. V. Alekseenko and A. A. Prikhod'ko, "Mathematical Modeling of Ice Body Formation on the Wing Airfoil Surface," Fluid Dynamics, vol. 49, no. 6, pp. 715-732, 2014.

[20] F. Saeed, C. Brette, M. Fregeau, O. Trifu and I. Paraschivoiu, "A Three-Dimensional Water Droplet Trajectory and Impingement Analysis Program," in 23rd Applied Aerodynamics Conference, Toronto, Canada, 2005.

[21] W. G. Habashi, F. Morency and H. Beaugendre, "FENSAP-ICE: A Comprehensivs 3D Simulation Tool for In-Flight Icing," in 7th International Congress of Fluid dynamics and Propulsion, Sharm-El-Sheikh, Egypt, 2001.

[22] C. R. Maliska, A. F. C. da Silva, R. A. Silveira, C. N. Donatti and G. L. Bridi, "Ice Accretion Prediction of Aerodynamic Bodies," in International Aerospace CFD Conference, Paris, 2007.

[23] Y. K. Choo, J. W. Slater, M. B. Vickerman and J. F. VanZante, "Geometry Modeling and Grid Generation for Computational Aerodynamic Simulations around Iced Airfoils and Wings," in 8th International Conference on Numerical Grid Generation in Computational Field Simulations, Honolulu, Hawaii, 2002.

[24] X. Chi, B. Zhu, T. I.-P. Shih, J. W. Slater, H. E. Addy and Y. K. Choo, "Computing Aerodynamic Performance of 2D Iced Airfoils: Blocking Topology and Grid Generation," in 40th Aerospace Sciences Meeting \& Exhibit, Reno, Nevada, 2002.

[25] Y. Cao, K. Chen and J. Sheridan, "Flowfield Simulation and Aerodynamic Performance Analysis of Complex Iced Airfoils with Hybrid Multi-block Grid," in Proceedings of the Institution of Mechanical Engineers, 2008.

[26] G. A. Ruff and D. N. Anderson, "Quantification of Ice Accretions for Icing Scaling Evaluations," in 36th Aerospace Sciences Meeting and Exhibit, Reno, Nevada, 1998.

[27] W. B. Wright and J. Chung, "Correlation Between Geometric Similarity of Ice Shapes and the Resulting Aerodynamic Performance Degradation - A Preliminary Investigation Using WIND," in 38th Aerospace Sciences Meeting and Exhibit, Reno, Nevada, 2000.

[28] D. E. Cook, "Relationships of Ice Shapes and Drag to Icing Condition Dimensionless Parameters," in 38th Aerospace Sciences Meeting \& Exhibit, Reno, Nevada, 2000.

[29] G. A. Ruff, "Quantitative Comparison of ICe Accretion Shapes on Airfoils," Journal of Aircraft, vol. 39, no. 3, pp. 418-426, 2002.

[30] Y. Cao, W. Tan and Z. Wu, "Aircraft Icing: An Ongoing Threat to Aviation Safety," Aerospace Science and Technology, vol. 75, pp. 353-385, 2018. 
[31] Z. Wu, "Drop "Impact" on an Airfoil Surface," Advances in collid and Interface Science, vol. 256, pp. 23-47, 2018.

[32] C. YiHua, Z. Guo and M. Chao, "Numerical Simulation of Ice Accretion Prediction on Multiple Element Airfoil," Science China Technological Sciences, vol. 54, no. 9, pp. 2296-2304, 2011.

[33] W. B. Wright, "Capabilities of LEWICE 1.6 and Comparison with Experimental Data," 1996.

[34] A. Lacroix and J. Manwell, "An Analytical Method for Assessing the Power Requirements of Wind Turbine Blade Anti-Icers," in 20th 2001 ASME Wind Energy Symposium, Reno, Nevada, 2001.

[35] A. O. Dairo, Y. -X. Tao and P. Tu, "Prediction of Ice Accretion on Wind Tturbine Blades - A User-Friendly Software," in 20th 2001 ASME Wind Energy Symposium, Reno, Nevada, 2001.

[36] P. K. Jha, D. Brillembourg and S. Schmitz, "Wind Turbines under Atmospheric Icing Conditions - Ice Accretion Modeling, Aerodynamics, and Control Strategies for Mitigating Performance Degradation," in 50th AIAA Aerospace Sciences Meeting including the New Horizons Forum and Aerospace Exposition, Nashville, Tennessee, 2012.

[37] X. Tong, D. Thompson, Q. Arnoldus, E. Collins and E. Luke, "Robust Surface Evolution and Mesh Deformation for Three Dimensional Aircraft Icing Applications on a Swept GLC-305 Airfoil," in 6th AIAA Atmospheric and Space Environments Conference, Atlanta, GA, 2014.

[38] L. Hu, X. Zhu, C. Hu, J. Chen and Z. Du, "Wind Turbines Ice Distribution and Load Response under Icing Conditions," Renewable Energy, vol. 113, pp. 608-619, 2017.

[39] H. Beaugendre, F. Morency and W. G. Habashi, "FENSAP-ICE: Roughness Effects on Ice Shape Prediction," in 41st Aerospace Sciences Meeting and Exhibit, Reno, Nevada, 2003.

[40] S. Nilamdeen, W. G. Habashi, M. S. Aubé and G. S. Baruzzi, "FENSAP-ICE: Modeling of Water Droplets and Ice Crystals," in 1st AIAA Atmospheric and Space Environments Conference, San Antonio, Texas, 2009.

[41] D. Switchenko, W. G. Habashi, G. Baruzzi and I. Ozcer, "FENSAP-ICE Simulation of Complex Wind Turbine Icing Events, and Comparison to Observed Performance Data," in 32nd ASME Wind Energy Symposium, National Harbor, Maryland, 2014.

[42] M. Virk, U. Mughal, Q. Hu and X. Jiang, "Multiphysics Based Numerical Study of Atmospheric Ice Accretion on a Full Scale Horizontal Axis Wind Turbine Blade," International Journal of Multiphysics, vol. 10, no. 3, pp. 237-245, 2016.

[43] M. Abbadi, I. Mussa, Y. Lin and J. Wang, "Preliminary Analysis of Ice Accretion Prediction on Wind Turbine Blades," Orlando, Florida, 2020.

[44] ANSYS, "FENSAP-ICE User Manual," ANSYS, 2017. 